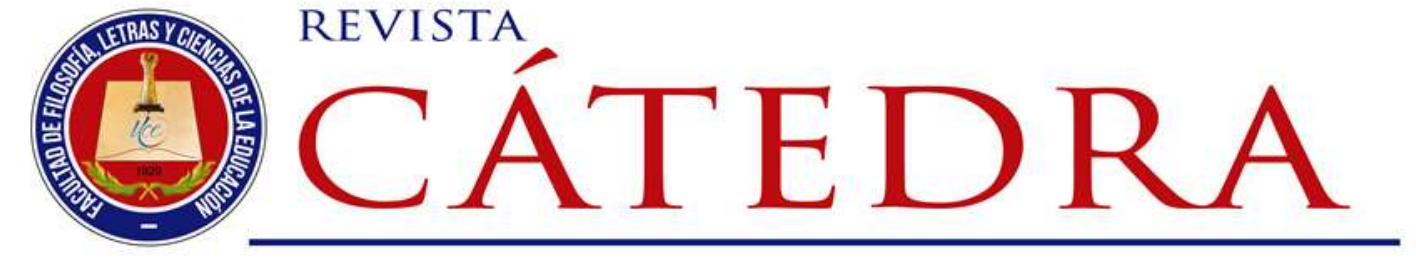

\title{
Retos y logros de la aplicación de grupos interactivos en una comunidad de aprendizaje
}

\section{Challenges and achievements of the implementation of interactive groups in a learning community}

Bolívar Villarreal-Yazán

Unidad Educativa Antisana, Quito, Ecuador

bolivar.villarreal@educacion.gob.ec https://orcid.org/0000-0002-7603-4077

Verónica Maila-Álvarez

Universidad Central del Ecuador, Quito, Ecuador mvmaila@uce.edu.ec https://orcid.org/0000-0002-4139-7636

Helen Figueroa-Cepeda Universidad Central del Ecuador, Quito, Ecuador hifigueroa@uce.edu.ec https://orcid.org/0000-0002-6305-487X

Elizabeth Pérez-Alarcón

Universidad Central del Ecuador, Quito, Ecuador eyperez@uce.edu.ec https://orcid.org/0000-0002-7739-5931

(Recibido: 01/12/2020 Aceptado: 15/12/2020; Versión final recibida: 07/01/2021)

Cita del artículo: Villarreal-Yazán, B., Maila-Álvarez, V., Figueroa-Cepeda, H. y Pérez-Alarcón, E. (2021). Retos y logros de la aplicación de grupos interactivos en una comunidad de aprendizaje. Revista Cátedra, 4(1), 56-80. 


\section{Resumen}

La presente investigación nace de la necesidad de evaluar los logros y retos respecto a la implementación de una nueva estrategia metodológica educativa propuesta en el Ecuador. Los objetivos que se plantearon fueron: 1) Evaluar la aplicación de los Grupos Interactivos como estrategia metodológica de aprendizaje. 2) Determinar las dificultades que afronta la institución en la fase de implementación. 3) Establecer los logros alcanzados. Este trabajo de tipo descriptivo y cualitativo considera como caso de estudio a la Unidad Educativa Antisana, institución ubicada en un contexto rural del Ecuador. Los instrumentos de investigación aplicados fueron la entrevista semiestructurada dirigida al rector y grupos focales a docentes, estudiantes y voluntarios. Los ámbitos de indagación convergieron en la gestión administrativa institucional, cualidades del docente, aplicación de la metodología de grupos interactivos y desempeño de los voluntarios. Los principales logros alcanzados fueron diálogo igualitario, transformación y solidaridad, como principios del aprendizaje dialógico, además del liderazgo estudiantil y la potenciación de la zona de desarrollo próximo. Se advirtieron dificultades en algunos estudiantes, docentes y voluntarios evidenciadas en la falta de empoderamiento, superficialidad de las actividades instrumentales y escasa participación, respectivamente. Los retos generados de esta primera experiencia giran en torno a la consolidación de la estrategia a través de la interiorización del enfoque de los grupos interactivos. Es necesario proponer actividades colaborativas e integrar a otros actores sociales en calidad de voluntarios. Aspectos que permitirán fortalecer la inclusión y la cohesión social.

\section{Palabras clave}

Actuaciones educativas, aprendizaje dialógico, didáctica, grupos interactivos, inclusión, innovación

\section{Abstract}

The present research was born from the need to evaluate the achievements and challenges regarding the implementation of a new educational methodological strategy proposed in Ecuador. The objectives were: 1) To evaluate the application of Interactive Groups as a methodological strategy for learning. 2) To determine the difficulties faced by the institution in the implementation phase. 3) To establish what has been achieved. This descriptive and qualitative work considers the Antisana Educational Unit as a case study, an institution located in a rural context in Ecuador. The applied research instruments were a semistructured interview with the rector and focus groups with teachers, students and volunteers. The areas of investigation converged on institutional administrative management, teacher qualities, application of the interactive group methodology, and volunteer performance. The main achievements were egalitarian dialogue, transformation and solidarity, as principles of dialogic learning, in addition to student leadership and the empowerment of the area of proximate development. Difficulties were noted in some students, teachers and volunteers evidenced in the lack of empowerment, superficiality of instrumental activities and low participation, respectively. The challenges generated from this first experience revolve around the consolidation of the strategy through the internalization of the interactive groups approach. It is necessary to propose collaborative activities and to integrate other social actors as volunteers. Aspects that will strengthen social inclusion and cohesion. 


\section{Keywords}

Educational actions, dialogic learning, didactics, interactive groups, inclusion, innovation.

\section{Introducción}

Los Grupos Interactivos (GI) constituyen una estrategia metodológica basada en los principios del aprendizaje dialógico. Esta estrategia ha sido implementada en algunos países de Latinoamérica y Europa como una alternativa para solucionar problemas educativos. Entre las dificultades detectadas están: problemas de convivencia, exclusión de estudiantes, escasa corresponsabilidad de la comunidad educativa y bajo rendimiento académico. Sobre la base del éxito obtenido en otros países, en el 2017 se implementaron en el Ecuador los GI como parte de las Comunidades de Aprendizaje (CdA) a nivel de Educación Básica y Media. La Unidad Educativa Antisana (UEA) fue seleccionada como aliada de las CdA para la implementación de los GI en su primera fase. En tal virtud, el propósito del presente estudio es valorar los resultados de esta primera vivencia en términos de logros y dificultades.

Los GI basan su éxito en los resultados educativos que trascienden el ámbito academicista. Al respecto, Ordóñez y Rodríguez (2016) expresan "los grupos interactivos favorecen el aprendizaje de los contenidos, las relaciones y solidaridad entre el alumnado y con el profesorado, la participación y cooperación en el trabajo en grupo" (pág. 151). Se reafirma la trascendencia de esta actuación educativa, ya que en el aula se crea un entorno de interacción social. La relación docente-estudiante pasa a segundo plano y son los diferentes actores sociales los nuevos protagonistas. Iglesias et al. (2013) señalan que los GI “... ha supuesto la apertura de los límites del instituto a la familia y al entorno educativo, produciéndose un aprendizaje más significativo por acercar al centro el marco de referencia de las experiencias de aprendizaje de los alumnos" (pág. 69). Los actores sociales potencian las diversas competencias tanto de pensamiento, comunicativas y de convivencia. La participación activa de la comunidad educativa en la escuela, consolida aprendizajes que adquieren más sentido y se hacen más significativos para el estudiante. Esto es posible en una comunidad de aprendizaje donde los grupos interactivos se nutren de las más diversas vivencias.

Otro beneficio fundamental de la aplicación de los GI es la inclusión. Este concepto marca el sello de identidad de los GI, basado en la heterogeneidad de los mismos. Su conformación se centra en este criterio, garantizando así, a través del diálogo y la interacción, la concreción del enfoque inclusivo. Castro et al. (2014) manifiestan que se debe considerar por ejemplo el “... género, nivel de aprendizaje, origen cultural, afinidad..." (pág. 175). El propósito es consolidar un equipo de trabajo con la más amplia diversidad de experiencias, opiniones, pensamientos, sentimientos y saberes. El solo hecho de ser parte de un grupo, de interactuar en el mismo y que sus opiniones sean tomadas en cuenta hace que esta estrategia logre su intención, incluir.

Pese a los beneficios que representa la ejecución de los GI, su implementación como una nueva estrategia metodológica implica retos. Estos desafíos están relacionados principalmente con el involucramiento de todos los miembros de la comunidad, el diseño de actividades instrumentales y el tiempo extra que requiere la implementación de la estrategia. Chocarro y Mollà (2017) expresan que el trabajo con GI precisa de “... una buena planificación de calendario y contar, a ser posible, con un gran número de voluntariado fijo. Esto sería lo ideal, ya que dicha estructura resulta complicada en centros que no reciben tanta ayuda" (pág. 64). Este hecho posiblemente se atribuye a la falta de compromiso de los 
actores sociales, quienes no están acostumbrados a participar de manera directa en las actividades escolares. Por otra parte, Ordoñez y Rodríguez (2016) señalan que "hay que dedicar mucho tiempo y esfuerzo para organizar los grupos, diseñar las actividades y muchas veces no es suficiente con el tiempo de trabajo en el centro" (pág. 153). No cabe duda que incursionar en una nueva estrategia educativa demanda de tiempo, esfuerzo y dedicación que no todos los actores están dispuestos a vivenciar.

Por lo expresado, es importante evaluar la aplicación de los GI en la UEA como un caso particular de estudio de carácter cualitativo. Los objetivos son establecer los logros alcanzados en la fase de implementación de los GI y determinar las dificultades que afronta la comunidad de aprendizaje durante su ejecución. Estos resultados permitirán a la UEA replantear acciones en próximas experiencias, con el fin de mejorar la convivencia escolar y consolidar los aprendizajes. Al ser este trabajo un estudio particular, una de las limitaciones que presenta es el impedir realizar generalizaciones sobre la base de los resultados obtenidos. Sin embargo, los hallazgos encontrados pueden ser un referente para otras instituciones que inicien esta experiencia.

Bajo este contexto, en el presente artículo se contextualiza a la institución educativa, se describe a las Comunidades de Aprendizaje y los Grupos Interactivos. Se citan los principales beneficios de la implementación de los Grupos Interactivos, algunas dificultades que entrañan su ejecución y trabajos relacionados con los mismos. Se detallan los materiales y métodos empleados en la investigación, así como los resultados y conclusiones que se derivan de la experiencia de la incorporación de los GI en la unidad educativa.

\section{Contexto de intervención}

La UEA, Jatun Yachana Huasi, que en español significa Casa Grande del Saber, pertenece a la Comunidad de Tolóntag-Marco, Parroquia de Píntag, Distrito Metropolitano de QuitoEcuador. Su entorno geográfico lo ubica en la Zona de amortiguamiento de la Reserva Ecológica Antisana. El segmento poblacional está integrado por mestizos en su mayoría con descendencia indígena. Los integrantes adultos y adultos mayores utilizan la lengua materna, el kichwa para la interacción coloquial. Sus ocupaciones principales lo constituyen la labranza de la tierra, ganadería menor y emprendimientos de carácter apícola, huertos familiares y artesanía. Estas actividades se alternan con empleos en la urbe, focalizados en la construcción y electricidad. En los últimos años, la población joven se ha sumado a estudios universitarios y actualmente ha surgido una nueva generación de profesionales en varias áreas, en la que destaca la educativa.

La UEA está conformada por el rector, diez docentes y 215 estudiantes. La institución oferta servicios educativos en los subniveles de Educación Básica Superior y Bachillerato General Unificado. Además, cuenta con el Proyecto de Educación Básica para Jóvenes y adultos (EBJA) implementado en el 2018.

El 01 de agosto del 2019, la UEA pasó a ser parte del proyecto de CdA a través del área de Educación del Grupo Faro (centro de investigación y acción independiente ecuatoriano) y del Ministerio de Educación del Ecuador. Para la implementación del proyecto se realizó un proceso de inducción a los distintos miembros de la comunidad educativa bajo la directriz del Grupo Faro. El acompañamiento fue responsabilidad del equipo de Asesoría Educativa, instancia adscrita al Ministerio de Educación. De las siete Actuaciones Educativas de Éxito (AEE) en las que se apoyan las CdA, la institución decidió trabajar con los GI y tertulias literarias.

Licencia Creative Commons Atribución 4.0 Internacional (CC BY 4.0)

Revista Cátedra, 4(1), pp. 56-80, enero-abril 2021. e-ISSN: 2631-2875

https://doi.org/10.29166/catedra.v4i1.2676 
En enero del 2020 se ejecutó el proyecto de GI en su primera fase. Este proceso se aplicó luego de un consenso con el equipo docente, como estrategia aplicable al cierre del Quimestre I, correspondiente al periodo lectivo 2019-2020. Acorde a calendario, la jornada académica fue programada para una semana.

\section{Conceptos relacionados}

\subsection{Comunidades de aprendizaje}

Comunidades de Aprendizaje es un proyecto de transformación social que inicia en la escuela y se expande a toda la comunidad. Su esencia radica en la participación de familiares y voluntarios en las decisiones y actividades escolares. En este contexto, es de suma importancia revisar los conceptos de: Comunidades de Aprendizaje, Aprendizaje Dialógico y Actuaciones Educativas de Éxito.

En una aproximación al primer concepto, Community of Research on Excellence for All (CREA, 2018a.) señala que "una Comunidad de Aprendizaje es un proyecto basado en un conjunto de actuaciones educativas de éxito dirigidas a la transformación social y educativa" (pág. 5). Los seres humanos, somos eminentemente sociales. Allí reside la importancia de que los actores y los contextos escolares y de su entorno consoliden aprendizajes significativos que lo identifican con su comunidad. Es ahí, en la comunidad, donde se reafirma la fortaleza de la interacción, sustentada en una profunda predisposición por aprender en complicidad con todos sus actores.

La interacción de la comunidad logra resignificación de sus paradigmas buscando siempre adaptaciones a estos nuevos sistemas. Al respecto, Flecha et al. (2003) manifiestan "... el desarrollo de este proyecto supone no adaptarse a las condiciones desfavorables del entorno sino transformarlas" (pág. 2). Se advierte cómo esta sinergia de los actores sociales, su entorno, su cultura, sus encuentros y desencuentros ligados por la interacción, propician nuevos ambientes. Es en este nuevo entorno donde se potencian los aprendizajes.

Picardo et al. (2005) corroboran lo enunciado en el párrafo anterior, al manifestar que:

CdA, es una visión ecológica e integral del aprendizaje, que implica no solo construcción, sino también deconstrucción y reconstrucción, a partir de una perspectiva multidimensional de la nueva sociedad del conocimiento, apuntando y apostando a verdaderos ambientes de aprendizaje ensamblados en la interacción dialógica; es nueva corriente que se sustenta en metodologías basadas en resolución de problemas de forma colectiva, experimentando soluciones de diversos puntos de vista sin que éstas sean excluyentes, y sobre todo posibilitando la creatividad e innovación (pág. 51).

En este sentido, la sinergia de estas experiencias se ve fortalecida en el diálogo y la solución de problemas propuestas por el docente. Él se convierte en una suerte de constructor de arquitecturas sociales. Este nuevo paradigma es el que se revitaliza a través del desarrollo y fortalecimiento de estilos de aprendizaje e inteligencias.

La sociedad del conocimiento se reafirma en la formación de perfiles requeridos dentro de un contexto socio-económico cada vez más demandante. De acuerdo a Ottone y Hopenhayn (2007), ya en el ámbito educativo son más precisos al enunciar y ratificar lo expuesto cuando se refieren a que "la educación que prefigura las funciones de futuro deberá tender

Licencia Creative Commons Atribución 4.0 Internacional (CC BY 4.0) 
a generar: capacidad de abstracción, desarrollo de un pensamiento sistémico complejo e interrelacionado, habilidad de experimentación y capacidad de colaboración, trabajo en equipo, interacción con los pares" (pág. 15). Se desprende que el imaginario de este nuevo entorno deberá poseer mucha más creatividad que docilidad u orden. La esencia social del ser humano, en este proceso, no puede consolidarse sin un gravitante primordial, la comunidad. La empatía grupal, el trabajo colaborativo y el reconocimiento de sí mismo se dan en este espacio.

Las CdA asientan sus objetivos en la necesidad imperiosa de que el estudiante potencie y fortalezca sus habilidades, destrezas y competencias cognitivas, práxicas y valorativas. Esto permitiría que la discusión se centre en la problemática social, dando paso a posibles soluciones que le asignen el derecho a una vida digna. Así lo citan Flecha et al. (2003), las CdA "es un proyecto que va dirigido especialmente a aquellos centros con más carencias, problemas de desigualdad y pobreza, en los que las condiciones externas parecen apuntar más hacia el fracaso escolar y la exclusión" (pág. 4). El enfoque debe ser eminentemente formativo e inclusivo y la estrategia dialógica, con énfasis en la escuela con la ayuda de la familia y la comunidad. De esta forma las brechas sociales y económicas tenderían a minimizarse.

El concepto de Aprendizaje Dialógico, se sustenta en los principios de las CdA, con enfoque interactivo. Aubert et al. (2008) describen cómo se genera el aprendizaje dialógico, sustentando a manera de definición, los componentes cuya base son los principios del mismo.

El aprendizaje dialógico se da por medio de diálogos igualitarios, en interacciones en las cuales se reconoce la inteligencia cultural en todas las personas. Esas interacciones están orientadas a la transformación de los niveles previos de conocimiento y del contexto sociocultural en búsqueda del éxito para todos. Además, el Aprendizaje dialógico se produce en las interacciones que aumentan el aprendizaje instrumental, favorecen la creación de sentido personal y social, están guiadas por principios solidarios y en las que la igualdad y la diferencia son valores compatibles y mutuamente enriquecedores (pág. 167).

Se advierte que la connotación del concepto de Aprendizaje Dialógico va más allá del hecho comunicativo, pues su fundamento se basa en las interacciones del ser social. Este, al enmarcarse en un contexto socio cultural, se significa y resignifica. Así se consolidan como seres que sienten, aprenden, se transforman, reconocen, crean y se dan sentido a sí mismos y a su entorno. Siendo así, desdice toda interacción que afirma relaciones de poder y peso de la estructura social inequitativa. Por el contrario, hace énfasis en la formación de seres humanos empoderados en los conceptos de solidaridad, igualdad y transformación social.

Ahora bien, como ya se expresó, una CdA se sustenta en el aprendizaje dialógico y a su vez para que éste se materialice es necesario que se cumplan siete principios, los cuales en resumen y de acuerdo a CREA (s.f.) son:

Diálogo igualitario: la fuerza está en los argumentos y no en la jerarquía de quien habla. Es escuchar con respeto y hablar con sinceridad. Inteligencia cultural: comprende el saber académico, práctico y comunicativo; todas las personas tienen capacidad de acción y reflexión. 
Transformación: educación como agente transformador de la realidad por medio de las interacciones.

Creación de sentido: Aprendizaje que parte de la interacción y las demandas y necesidades de las propias personas.

Solidaridad: participación solidaria de todas las personas de la comunidad en el proyecto educativo de la escuela.

Dimensión instrumental: aprendizaje de los instrumentos fundamentales para la inclusión en la sociedad actual.

Igualdad de diferencias: mismas oportunidades para todas las personas (pág. 16).

Con este sustento epistemológico se llega al espacio educativo. Para la implementación del modelo se recurre a las denominadas AEE, que son estrategias educativas que promueven el desempeño académico, la convivencia y la solidaridad. Las AEE con las cuales una CdA concreta sus objetivos en la escuela son: grupos interactivos, tertulias dialógicas, biblioteca tutorizada, formación de familias, participación educativa de la comunidad, modelo dialógico de prevención y resolución de conflictos y formación pedagógica dialógica. Todas ellas basan su accionar en la interacción. Los GI, por su dinámica, es quizá una de las que armoniza todos los principios del aprendizaje dialógico. De allí, la intencionalidad de la descripción de la aplicación de esta estrategia en una experiencia educativa.

\subsection{Grupos interactivos}

Los GI constituyen una de las estrategias educativas innovadoras contempladas dentro del proyecto Comunidades de Aprendizaje. Es una de las AEE que se han venido aplicando en las instituciones educativas con mayor frecuencia. De acuerdo a Andrés Reina (2016):

... son cada vez más los centros que están desarrollando en sus aulas este tipo de agrupamiento, puesto que las investigaciones demuestran que están dando unos estupendos resultados. Los resultados positivos no solo son en sentido numérico o académico, si no también, y aún más importante, se obtienen muchas mejoras a nivel de convivencia, motivación y habilidades sociales (pág. 17).

La práctica educativa denota que en el aula en mucha de las ocasiones se da prioridad a la transmisión de información. El quehacer educativo debe desarrollar, potenciar y fortalecer competencias comunicativas, competencias para una mejor convivencia humana y naturalmente competencias cognitivas. De allí la importancia de trabajar las destrezas y habilidades que permitan consolidar estas competencias en los estudiantes en los distintos espacios de inter-aprendizaje.

Se describe en las siguientes líneas con mayor detalle qué son los GI, en qué consisten y cuál es el rol de los participantes.

\subsection{1 ¿Qué son los Grupos Interactivos?}

Existen dos concepciones respecto al concepto GI, una de ellas basada en la estructura organizacional del aula y la otra, un tanto más amplio, vista como una práctica didáctica. Así Andrés Reina (2016) expresa "se trata de una forma de organizar a los alumnos dentro del aula, se forman pequeños grupos de 4 o 5 componentes cada uno" (pág. 13). Oliver y Gatt (2010), por su parte enfatizan el valor de los GI al señalar que “... son una de las formas de organización de las aulas que está obteniendo más éxito en Europa en la superación del fracaso escolar y los problemas de convivencia" (pág. 279). Dentro de esta misma 
concepción, en CREA (2018b) se enuncia que "los Grupos Interactivos son una forma de organización del aula en grupos reducidos y heterogéneos y con una redistribución de los recursos humanos disponibles" (pág. 15). Se advierte que las tres fuentes conjugan en que los GI son una forma de organización de los estudiantes en el aula. El aporte más evidente está dado en la intencionalidad, cuando se afirma que el fracaso escolar y los problemas de convivencia son los fines a trabajar. Al mismo tiempo ya se habla del número de integrantes y del enfoque inclusivo.

Con una visión más amplia, Castro et al. (2014) expresan que "los grupos interactivos trasladan al aula los principios del aprendizaje dialógico, por lo que suponen un cambio sustancial respecto al modo magistral tradicional de hacer las clases, pero también respecto a otras formas no tradicionales de agrupación del alumnado" (pág. 175). Bajo este pensamiento, se ve a los GI como el medio que permite desarrollar un aprendizaje colaborativo, entre pares. Proceso en el que se cuenta con el aporte de cada uno de los participantes, pues todos parten de su experiencia cultural y se proyectan a un mismo objetivo. En esta experiencia pedagógica ya se asientan los principios del aprendizaje dialógico y la ruptura de la clásica forma de estructurar una clase. Este salto estratégico permite desarrollar aprendizajes a través de la interacción en nuevas formas de comunidad.

\subsection{2 ¿En qué consisten?}

Los GI tienen una estructuración que se ciñe a cuatro pasos elementales. CREA (2018b), los resume en los siguientes: organización de grupos pequeños de trabajo; asignación de una persona adulta a cada grupo; ejecución de la actividad asignada en cada grupo y bajo el acompañamiento del adulto; rotación de grupos a una actividad distinta y con un adulto diferente (pág. 16).

Estos cuatro pasos se detallan con el aporte de otros autores. Con respecto a la conformación de los grupos de trabajo es de suma importancia que éstos sean pequeños de 4 a 5 estudiantes y heterogéneos. Castro et al. (2014) expresan que se debe procurar que los integrantes presenten las más variadas características en todos los ámbitos posibles. Entre los aspectos a considerar se citan el "... género, nivel de aprendizaje, origen cultural, afinidad..." (pág. 175). Cuanta más diversidad se consiga entre los estudiantes, mejor, pues esta condición de heterogeneidad garantiza que ningún estudiante se sienta aislado por la condición que fuese.

A cada grupo conformado se le designa un adulto, quien también recibe la denominación de voluntario o tutor. Esta persona puede ser cualquier miembro cercano o no a la comunidad de aprendizaje. Castro et al. (2014) proponen como voluntarios a las "abuelas, abuelos, madres, padres, hermanos y hermanas mayores u otros familiares, amistades o agentes sociales del entorno" (pág. 175). No se descarta la participación de adultos fuera del barrio o de contextos lejanos a los educandos como los estudiantes universitarios. Se infiere que, todo ciudadano comprometido con el porvenir de la sociedad es bienvenido a participar de manera directa y activa en el proceso educativo.

Los voluntarios no necesitan de requisito alguno para su participación. Al respecto, los citados autores señalan “... es innecesario que los tutores o las tutoras de los pequeños grupos sepan acerca de los contenidos que el alumnado trabaja en clase: para eso ya está el profesorado" (pág. 175). Por supuesto, su empatía con autoridades y docentes juega un papel muy significativo en la consecución de los objetivos de aprendizaje. Además, bajo este 
ambiente ausente de exigencias, se busca que el desempeño de los voluntarios se realice de manera espontánea y libre de temores.

En lo concerniente a la ejecución de actividades, se deben tomar en consideración la duración y naturaleza de las mismas. Castro et al. (2014) señalan "en las aulas donde se llevan a la práctica los grupos interactivos, es habitual que el grupo-clase se divida en 4 ó 5 pequeños grupos que realizan tareas de unos 15 o 20 minutos con el tutor o tutora adulta" (pág. 176). Con respecto al tipo de actividades, los mismos autores indican que se debe "establecer estrategias de enseñanza-aprendizaje orientadas a la dimensión instrumental del aprendizaje, con el propósito de capacitarles para responder a las demandas que se les van a plantear en la sociedad de la información" (pág. 178). Por lo tanto, se infiere la importancia de llevar al aula acciones o ejercicios debidamente planificados. Las actividades propuestas no deben limitarse a reforzar el aspecto cognitivo, que en última instancia es el ámbito de menor interés dentro del propósito de la aplicación de los GI. Por el contrario, se debe retar a los estudiantes a dar solución a los problemas planteados a través de su capacidad de toma de decisiones.

Sobre la rotación de los grupos, Oliver y Gatt (2010) señalan que "los grupos interactivos favorecen, al mismo tiempo, la rotación dinámica de diversas actividades de aprendizaje instrumental en una sola sesión, de manera que todo el alumnado (no solo el más aventajado) acaba realizando todas las actividades programadas para esa sesión" (pág. 282). En sí, la rotación de tareas y voluntarios dinamiza el proceso educativo al ampliar los campos de aprendizaje y las interacciones en diferentes escenarios.

\subsection{3 ¿Cuál es el rol de los participantes?}

La ejecución correcta de los cuatro pasos antes citados son la base para el éxito de la aplicación de los GI, por ello cada uno de los participantes debe conocer y cumplir a cabalidad con sus responsabilidades. Este equipo de trabajo lo constituye el profesor responsable de la asignatura, voluntarios y estudiantes.

El rol del profesor tal como lo señala Andrés Reina (2016) se resume en la planificación del proceso de aprendizaje, asesoramiento y evaluación en la gestión de los GI:

En cuanto al papel del profesor, se encamina a coordinar la actividad y a organizar la responsabilidad a la que cada uno tendrá que hacer frente. También es tarea del docente vigilar que se desarrollen los contenidos, tanto los académicos como los que se refieren a las habilidades que se pretenden adquirir o fomentar. Seleccionar los contenidos a trabajar, diseñar actividades, organizar los grupos de manera heterogénea, compartir estas actividades con las personas que van a colaborar en el aula, atender a las necesidades que surjan, servir de apoyo extra a los estudiantes que lo necesiten y al finalizar la sesión, realizar una evaluación con los voluntarios y alumnos (pág. 14).

Si bien el rol de cada participante es importante en el desarrollo de los GI, es necesario hacer énfasis en el rol de liderazgo que tiene el profesor como profesional educativo. El educador conoce a sus estudiantes, sus características, intereses, fortalezas y debilidades. En base a este conocimiento, es la persona indicada para canalizar las actividades, así como optimizar los recursos con criterio técnico.

Licencia Creative Commons Atribución 4.0 Internacional (CC BY 4.0)

Revista Cátedra, 4(1), pp. 56-80, enero-abril 2021. e-ISSN:2631-2875

https://doi.org/10.29166/catedra.v4i1.2676 
El voluntario o tutor tiene bajo su responsabilidad el ámbito operativo y logístico, sobre todo estableciendo canales de comunicación entre los integrantes del equipo de trabajo. A decir de Rodríguez (2012):

El voluntario, que previamente ha recibido formación, no desempeña un rol de experto, sí se encarga de favorecer el diálogo, de asegurarse de que han comprendido la tarea, de dinamizar el trabajo en los grupos, de evitar actitudes de aislamiento y de conseguir que todos participen en la resolución de la tarea (pág. 72).

Este actor social se consolida como apoyo fundamental dentro de los GI. Su experiencia como jefe de hogar, líder, microempresario, emprendedor y estudiante lo convierten en mediador. El perfil del voluntario posibilita la interacción espontánea desde otros niveles de expectativa.

El alumnado por su parte tiene el compromiso de colaborar de manera activa en el cumplimiento de las tareas asignadas. Castro et al. (2014) enfatizan que es "... el propio alumnado, mediante la cooperación y el diálogo con sus iguales, el que resuelve las dificultades que se le presenten" (pág. 175). Esta experiencia educativa aplicada como estrategia pedagógica en el aula reafirma el concepto de CdA. La interacción de sus actores posibilita nuevas sinergias, las mismas que se traducen en destrezas y habilidades de la más diversa índole. Esto beneficia de manera directa al segmento estudiantil, e indirectamente a voluntarios y docentes que en esta experiencia dialógica fortalecen inter-aprendizajes.

\subsection{Beneficios y limitaciones de la aplicación de los Grupos Interactivos}

Los GI como parte de las metodologías activas de las Comunidades de Aprendizaje generan múltiples beneficios. La diversidad de interacciones entre los actores que esta estrategia metodológica demanda, permite el desarrollo de habilidades cognitivas, actitudinales y fundamentalmente promueve las habilidades sociales. Así lo manifiestan Ordóñez y Rodríguez (2016), "los grupos interactivos favorecen el aprendizaje de los contenidos, las relaciones y solidaridad entre el alumnado y con el profesorado, la participación y cooperación en el trabajo en grupo" (pág. 151). Esta estrategia contempla el desarrollo holístico del estudiante, dado que promueve, además de las habilidades cognitivas, el fortalecimiento de las habilidades sociales. Estas destrezas son indispensables para que el individuo se desenvuelva de forma efectiva en la comunidad a la que pertenece.

Los GI, al estar conformados por pequeños grupos heterogéneos como requisito fundamental de los mismos, permiten cumplir con el principio de inclusión escolar. En la educación tradicional, los estudiantes con habilidades educativas especiales, de diferente origen étnico o de condición socioeconómica distinta a la mayoría de sus compañeros quedan relegados, subvalorados e inclusive discriminados. Como una solución a este problema, los GI potencian la educación inclusiva, esta afirmación lo corroboran Iglesias et al. (2013):

Las metodologías docentes tradicionales se ven tremendamente limitadas cuando se enfrentan a un alumnado variado. ¿Cómo atender a todos?, ¿cómo conseguir que todas y todos trabajen y aprendan, y que lo hagan juntos? La respuesta por la que se ha venido apostando, y hacia donde apuntan las políticas educativas predominantes actuales, es la segregación: agrupar a los alumnos por nivel curricular o sacarlos del aula de referencia según sus dificultades para darles una respuesta que a 
menudo se puede dar en el aula de forma más eficaz e integradora aplicando estrategias metodológicas más inclusivas como la de los grupos interactivos (pág. 65).

Por lo tanto, los GI se constituyen en una excelente alternativa para incorporar a estudiantes con necesidades educativas especiales (NEE) al trabajo escolar cotidiano. Bajo el principio de inclusión, los estudiantes que participan en los GI aprenden a ser más tolerantes, a respetar la diversidad de opiniones y mostrar empatía. Además, los estudiantes aprenden a trabajar colaborativamente de acuerdo a sus habilidades y capacidades. Según lo que expresan Valls y Kyriakides (2013), todos los integrantes del grupo aportan significativamente. Ningún miembro queda relegado y mas bien se mantienen altas expectativas de todos, e inclusive se reduce la necesidad de realizar diferenciaciones curriculares de aquellos considerados como diferentes (págs. 24-25). La estrategia de los GI puede reducir significativamente la necesidad de realizar adaptaciones curriculares. Los miembros del grupo apoyan a sus compañeros que presentan dificultades e inclusive bajo este esquema de trabajo pueden sobresalir al desarrollar otras habilidades.

En la aplicación de los GI también resalta el desarrollo o potenciación de los procesos cognitivos. Gracias a la interacción entre iguales y la comunicación asertiva se mejora la compresión y refuerzan temáticas que de forma individual requerirían de mayor esfuerzo. Este hecho lo mencionan Valls et al. (2016), "las interacciones dan proximidad a la explicación, desarrollan habilidades comunicativas, generando múltiples procesos cognitivos. De esta forma, se consolida lo aprendido, aumentan los niveles de comprensión y aprendizaje" (pág. 21). Los GI, al permitir el diálogo entre iguales, favorecen el desarrollo de las capacidades intelectuales e incluso mejoran el rendimiento académico. Gracias a la dinámica de esta estrategia se reducen las barreras de la inequidad y exclusión a la que están sujetos especialmente los grupos de riesgo.

Un beneficio adicional que vale la pena resaltar con relación a la aplicación de los GI es la consolidación de la comunidad educativa. El rol del padre de familia, quien generalmente es el voluntario, adquiere mayor protagonismo. Así lo manifiestan Iglesias et al. (2013):

La puesta en marcha de la propuesta metodológica de los grupos interactivos ha supuesto la apertura de los límites del instituto a la familia y al entorno educativo, produciéndose un aprendizaje más significativo por acercar al centro el marco de referencia de las experiencias de aprendizaje de los alumnos. El profesorado crea canales de comunicación e intercambio con las personas voluntarias y así la comunidad educativa se fortalece de una forma activa y motivadora (pág. 69).

La presencia de los voluntarios en los GI favorece la comunicación e interacción en la comunidad educativa. Los voluntarios constituyen una fuente de motivación como también un aporte por la diversidad de experiencias y riqueza cultural que éstos pueden aportar al grupo. Además, por ser personas adultas pueden ayudar a guiar y resolver potenciales conflictos en el grupo. Los GI constituyen sin duda una excelente manera para dinamizar el proceso de enseñanza aprendizaje, haciéndolo más activo, atrayente e inclusivo, fortaleciendo la comunidad educativa.

A pesar de todos los beneficios que aportan los GI, existen algunas limitaciones para la aplicación de los mismos. Una de estas limitaciones está relacionada con la participación de los voluntarios, en especial con padres de familia que pertenecen a nivel de colegio en donde se observa un menor compromiso. En la investigación realizada por Ordoñez y Rodríguez

Licencia Creative Commons Atribución 4.0 Internacional (CC BY 4.0) 
(2016) se resalta que "una de las limitaciones de esta investigación es la formación y colaboración del voluntariado. En muchas ocasiones cuando fallan hay que reorganizar sobre la marcha la dinámica de GI" (pág. 153). No cabe duda que si no existe compromiso por parte de los voluntarios al participar en la estrategia, el docente no podrá cumplir con las actividades planificadas. Además, se verá obligado a reestructurar los grupos haciéndolos más grandes, lo que contradice la propuesta metodológica.

Otra de las limitaciones en la implementación de los GI es la gran cantidad de trabajo que demanda por parte del docente. Así lo menciona Andrés Reina (2016), "no todos los docentes de un centro educativo están dispuestos a innovar en sus aulas. La innovación conlleva el trabajo extra de conocer las necesidades de cada uno de los alumnos, estudiar sus necesidades, adaptar los aprendizajes, etc." (pág. 48). Bajo esta premisa, algunos docentes no están interesados en incorporar estrategias nuevas a su práctica educativa. Además, la inexperiencia puede llevar al maestro a proponer tareas típicas del trabajo individual o que éstas no impliquen un desafío para los estudiantes. Según Álvarez (2016), las actividades propuestas deben "... ser de repaso, para afianzar los procesos de resolución de ejercicios en las principales áreas implicadas, siempre instrumentales, y deben a su vez suponer un cierto desafío en su resolución, para estimular al máximo el desarrollo de los estudiantes" (pág. 134). Las actividades propuestas deberán representar un reto para los estudiantes. En este sentido, los docentes requieren de un buen proceso de formación y acompañamiento en la implementación de los GI. Si no se planifican y diseñan con cuidado las actividades a desarrollar en la implementación de la estrategia, esta experiencia no trascenderá en el fin último que es la transformación de la comunidad educativa.

\section{Trabajos relacionados}

Al constituirse los GI en una estrategia didáctica alternativa, inclusiva y participativa es apropiado revisar brevemente trabajos cuyos resultados respaldan el éxito de los mismos. Se describen trabajos a nivel de Europa, Latinoamérica y Ecuador.

En el trabajo de investigación Análisis de las interacciones entre alumnado y diversas personas adultas en actuaciones educativas de éxito: Hacia la inclusión de todos y todas, desarrollado en España se planteó como objetivo analizar las interacciones que se generan a partir de los GI y tertulias literarias dialógicas. Además, se verificó cómo estas estrategias favorecen la creación de ambientes inclusivos de aprendizaje. El estudio fue de carácter cualitativo realizado en dos instituciones educativas y focalizado en estudiantes con NEE. Destacan como resultados la identificación de tres tipos de interacciones: superación de dificultades de aprendizaje, creación de nuevas oportunidades de aprendizaje e interacciones que favorecen la participación de estudiantes con NEE. Se llegó a la conclusión que las AEE analizadas promueven la inclusión, generan diversidad de aprendizajes y promueven desafíos cognitivos (García et al., 2016).

El estudio realizado por Zubiri et al. titulado Inclusión, participación y colaboración: Aprendiendo en grupos interactivos ejecutado en España tuvo como propósito explorar las oportunidades que generaron los GI en el aprendizaje del inglés como segunda lengua. A través de un enfoque cualitativo se analizó la información obtenida en tres instituciones educativas diferentes. Entre los principales resultados se menciona que los GI fomentan las interacciones colaborativas, promueven la inclusión y la participación de todos los estudiantes. En conclusión, el estudio señala que la estrategia de los GI crea condiciones favorables para el aprendizaje de inglés u otros idiomas como lengua extranjera (Zubiri et al., 2020). 
El trabajo de investigación realizado por Álvarez Comunicación, entendimiento y aprendizaje en grupos interactivos se desarrolla en dos escuelas de España y una de Brasil. Su objetivo fue determinar las interacciones en el ámbito comunicacional que se generan entre niños, niñas y personas adultas al trabajar en el aula a través de grupos interactivos. Se trata de un estudio de índole etnográfico basado en el método de estudio de casos. El análisis involucró las asignaturas de lengua y matemática para las dos escuelas españolas y lengua para la escuela brasileña. Las tres escuelas parten de condiciones de exclusión social. Los resultados giraron en torno a la comunicación, al entendimiento y al aprendizaje. En conclusión, se señala que los GI desarrollan las habilidades sociales de diálogo y acuerdo, aprendizajes significativos y valores (Álvarez, 2017).

Entre los trabajos a nivel de América Latina se cita la investigación Grupos interactivos en aula y el incremento de los resultados de aprendizaje en lenguaje en un colegio vulnerable realizado en Chile. El estudio incorporó GI en el aula de primero básico en la asignatura de Lenguaje. Su objetivo fue la determinación del incremento de los resultados de aprendizaje en dicha área. Se trata de un estudio cuantitativo cuyos resultados evidenciaron una diferencia significativa entre el pretest y el post test. La diferencia significativa se marca en la comprensión lectora y manejo de la lengua, no así en la elaboración de textos. No obstante, se concluye que a través de la aplicación de los GI se mejora en el desarrollo del lenguaje en la comprensión lectora, elaboración de textos y manejo de la lengua (Núñez et al., 2017)

En Ecuador Creamer, actual Ministra de Educación, realizó la investigación Transformación de la escuela en el marco de la implementación de comunidades de aprendizaje en Ecuador. El trabajo tiene por objeto la comprensión de las implicaciones que surte en la educación la implementación del modelo de CdA. Si bien el proyecto se ha desarrollado en trece instituciones educativas, se hizo el seguimiento en dos escuelas de las regiones Sierra y Costa. El estudio nació de la necesidad de incrementar la participación de los miembros de la comunidad educativa y de la posibilidad de involucramiento de sus estamentos. Hechos que pudieran lograrse mediante el establecimiento de relaciones dialógicas que fomentarían la calidad de los aprendizajes, la inclusión y la cohesión social (Creamer, 2019).

\section{Métodos y materiales}

La investigación tiene enfoque cualitativo y aplica el método de estudio de casos. A continuación, se describen los pasos desarrollados:

1. Ubicación del área de estudio. La investigación se focalizó en la UEA ubicada en PíntagTolóntag, en un área rural del cantón Quito.

2. Selección de la muestra. Se contó con la participación del rector, cinco docentes, cinco estudiantes del BGU y cinco madres de familia.

3. Diseño y aplicación de los instrumentos de investigación: Las técnicas aplicadas para recolectar información fueron entrevista semiestructurada y grupos focales. La entrevista estuvo dirigida al rector de la institución educativa y los grupos focales a docentes, estudiantes y voluntarios. El guion de preguntas tanto para la entrevista como para los grupos focales se relacionó con las dimensiones: gestión administrativa institucional, cualidades del docente, aplicación de la metodología de GI, logros del aprendizaje dialógico y desempeño de los voluntarios. En cada grupo focal los participantes fueron identificados a través de una codificación propia. Para los docentes se empleó la codificación [D] asignando el número de acuerdo al orden de intervención. Igual criterio se aplicó para la codificación de estudiantes [E] y voluntarios [V].

Licencia Creative Commons Atribución 4.0 Internacional (CC BY 4.0)

Revista Cátedra, 4(1), pp. 56-80, enero-abril 2021. e-ISSN:2631-2875

https://doi.org/10.29166/catedra.v4i1.2676 
4. Procesamiento de los datos. Una vez aplicados los instrumentos de investigación se realizó la trascripción de la entrevista y grupos focales. Luego se crearon los códigos y se seleccionaron las citas respectivas. Esta información se registró en una matriz que a su vez fue exportada al programa Atlas ti. Con ayuda del programa se elaboró una red semántica por cada dimensión, en las que se establecieron el tipo de relación entre los códigos.

5. Análisis y discusión de resultados. Sobre la base de la matriz de códigos y citas relevantes, junto con las redes semánticas se realizó la teorización y discusión de resultados. Se compararon los mismos con investigaciones similares relacionadas con la experiencia en la aplicación de los GI. Además, se tomó como referencia información de los conceptos relacionados. Finalmente, se elaboraron las conclusiones del estudio.

\section{Resultados y discusión}

\begin{tabular}{|c|c|c|}
\hline DIMENSIÓN & CóDIGOS & CITAS RELEVANTES \\
\hline \multirow{10}{*}{$\begin{array}{c}\text { Gestión } \\
\text { administrativa } \\
\text { institucional }\end{array}$} & Motivación [D, E, V] & "Siempre $\quad$ fortalece $\quad$ el \\
\hline & Motivación y satisfacción [A] & motivacional" [D2] \\
\hline & Socialización $[A, E, V]$ & "El señor rector puso todo \\
\hline & Participación $[\mathrm{A}, \mathrm{V}]$ & entusiasmo" [E4] \\
\hline & Empoderamiento de la autoridad [D, E] & "Todos sabíamos cómo debíamos apoyar \\
\hline & Compromiso [D] & en este proyecto" [V3] \\
\hline & Organización $[A, E]$ & "Está muy interesado en el proyecto. \\
\hline & Implementación $[\mathrm{A}, \mathrm{E}]$ & Siempre está allí bien atento a las cosas" \\
\hline & Seguimiento $[\mathrm{A}]$ & [E2] \\
\hline & Liderazgo $[\mathrm{A}]$ & $\begin{array}{l}\text { "Si estuvo el licenciado capacitándonos" } \\
\text { [V1] }\end{array}$ \\
\hline \multirow{10}{*}{$\begin{array}{c}\text { Cualidades del } \\
\text { docente }\end{array}$} & Actitud cooperativa $[\mathrm{A}, \mathrm{D}]$ & "Siempre $\quad$ estamos $\quad$ nosotros \\
\hline & Actitud solidaria $[\mathrm{D}, \mathrm{E}]$ & corrigiéndonos, estamos ayudándonos" \\
\hline & Predisposición docente $(\mathrm{A}, \mathrm{D}, \mathrm{E}, \mathrm{V}]$ & [D1] \\
\hline & Actitud cooperativa y empoderamiento docente [V] & "Están dispuestos a dar lo mejor de ellos" \\
\hline & Empoderamiento docente $[\mathrm{A}, \mathrm{D}, \mathrm{E}]$ & [V5] \\
\hline & Compromiso docente $[\mathrm{A}, \mathrm{D}]$ & "El 95 del $100 \%$ del equipo humano se \\
\hline & Liderazgo docente $[\mathrm{E}]$ & sumó, se empoderó" [A1] \\
\hline & Motivación y liderazgo docente [V] & "Buscaban una solución o trataban de \\
\hline & Motivación y creatividad docente [V] & arreglar eso, siempre con una buena \\
\hline & Empoderamiento y liderazgo docente [V] & actitud" [E2] \\
\hline \multirow{13}{*}{$\begin{array}{l}\text { Aplicación de } \\
\text { la metodología } \\
\text { de Grupos } \\
\text { Interactivos }\end{array}$} & Asesoramiento docente [V] & "Se exigió que los grupos sean formados \\
\hline & Conformación de grupos heterogéneos $[\mathrm{A}, \mathrm{D}, \mathrm{E}, \mathrm{V}]$ & con equidad de género ... y dentro de los \\
\hline & Asignación de un voluntario por grupo $[\mathrm{E}, \mathrm{V}]$ & grupos como tales deben estar inmersos \\
\hline & Diversidad y creatividad de actividades $[\mathrm{A}, \mathrm{V}, \mathrm{D}]$ & estudiantes con necesidades educativas" \\
\hline & Rotación de grupos [V] & [A1] \\
\hline & Conformación de grupos grandes [D] & "Todos los grupos ya estaban \\
\hline & Dificultad conformación grupos heterogéneos [D] & organizados de seis a siete estudiantes" \\
\hline & Reto en la planificación $[\mathrm{A}, \mathrm{E}]$ & [V4] \\
\hline & Evaluación de la actividad [V] & "También nos ponían ejercicios de \\
\hline & Actividades con enfoque cognitivo $[\mathrm{A}, \mathrm{D}, \mathrm{E}]$ & exámenes anteriores" [E5] \\
\hline & Manejo de tiempos $[\mathrm{A}, \mathrm{D}, \mathrm{E}, \mathrm{V}]$ & "Nos trajo retos nuevos a nosotros de \\
\hline & Dificultad en el cumplimiento de tiempos [D, V] & saber comprender bien cómo se iba a \\
\hline & Reto en la aplicación de la metodología [A, D] & desarrollar esta metodología" [D1] \\
\hline \multirow{15}{*}{$\begin{array}{l}\text { Logros del } \\
\text { Aprendizaje } \\
\text { dialógico }\end{array}$} & Diálogo igualitario y dimensión instrumental (E] & "Aprendí a escuchar a las demás \\
\hline & Dimensión instrumental $[\mathrm{A}, \mathrm{D}, \mathrm{E}, \mathrm{V}]$ & personas, escuchar su opinión, \\
\hline & Creación de sentido [D] & ayudarnos mutuamente" [E2] \\
\hline & Motivación estudiantil [D] & "Aprendí que podemos lograr cosas \\
\hline & Inteligencia cultural $[\mathrm{A}, \mathrm{E}]$ & increíbles con la unión de los \\
\hline & Diálogo igualitario $[\mathrm{A}, \mathrm{D}, \mathrm{E}, \mathrm{V}]$ & compañeros" [E4] \\
\hline & Transformación $[\mathrm{A}, \mathrm{D}, \mathrm{E}]$ & "Se descubrió liderazgos de guaguas que \\
\hline & Solidaridad e igualdad de diferencias [E] & tu realmente decías ¿y él está dirigiendo \\
\hline & Igualdad de diferencias $[\mathrm{E}, \mathrm{V}]$ & al grupo?" [D1] \\
\hline & Solidaridad $[\mathrm{A}, \mathrm{D}, \mathrm{E} \mathrm{V}]$ & "Trabajé con un compañero mío que \\
\hline & Solidaridad y diálogo igualitario [D, E] & tiene una capacidad diferente ... ese \\
\hline & Liderazgo estudiantil [D, E, V] & compañero tiene ganas de aprender ... \\
\hline & Predisposición estudiantil [E] & era bonito poder escucharle y saber la \\
\hline & Zona de desarrollo próximo [E] & manera en que piensa" [E1] \\
\hline & Falta de empoderamiento de algunos estudiantes $[\mathrm{E}, \mathrm{V}]$ & \\
\hline
\end{tabular}




\begin{tabular}{|c|c|c|}
\hline & & $\begin{array}{l}\text { "Algunos como que se confiaban y no } \\
\text { estudiaban, no ayudaban" [E3] }\end{array}$ \\
\hline \multirow{11}{*}{$\begin{array}{l}\text { Desempeño de } \\
\text { los voluntarios }\end{array}$} & Cumplimiento rol del voluntario $[\mathrm{A}, \mathrm{D}, \mathrm{E}, \mathrm{V}]$ & "Les ayudaba a que revisen las preguntas \\
\hline & Función operativa $[\mathrm{A}]$ & 1,2 veces lean para que sepan lo que \\
\hline & Rol de mediador $[\mathrm{D}, \mathrm{E}, \mathrm{V}]$ & tienen que poner" [V1] \\
\hline & Compromiso con la institución [V] & "Nos apoyaron en la parte de la \\
\hline & Empoderamiento del voluntario $[\mathrm{D}, \mathrm{V}]$ & organización..." [D5] \\
\hline & Motivación del voluntario [D, E, V] & "No nos dejaban que ... estemos jugando, \\
\hline & Empatía con el docente $[\mathrm{A}, \mathrm{D}, \mathrm{V}]$ & o que solo uno piense o que estemos \\
\hline & Empatía con los estudiantes [E] & copiando... estaban muy pendientes de \\
\hline & Predisposición a continuar en el proceso [A, V] & nosotros" [E2] \\
\hline & Falta de compromiso de algunos voluntarios [D] & "Me daría gusto volver a participar" [V1] \\
\hline & Incumplimiento rol de mediador [D] & $\begin{array}{l}\text { "... ponerme por dos días en los zapatos } \\
\text { de los licenciados y no es nada fácil" [V5) } \\
\text { "No tuvimos al } 100 \% \text { una participación } \\
\text { de los padres de familia" [D2] }\end{array}$ \\
\hline
\end{tabular}

Como se muestra en el cuadro 1 bajo la dimensión gestión administrativa institucional, docentes, estudiantes y voluntarios reconocen el rol fundamental de la autoridad en la implementación de los GI. El rector despertó y fortaleció el aspecto motivacional al transmitir su entusiasmo en cada una de las etapas del proceso. Todos los participantes de la comunidad educativa recibieron la socialización y capacitación sobre la dinámica de la estrategia, así como el rol que cada uno debía cumplir. Se rescata como código importante el liderazgo, lo que implicó como autoridad, involucrar a toda la institución dentro del proyecto, instando por la implementación inmediata.

En experiencias similares Álvarez (2016) expresa que es indispensable “... contar con un 'equipo de formación, apoyo y evaluación' que contribuya a situar las buenas prácticas de los grupos interactivos..." (pág. 134). En este sentido, es meritorio resaltar el rol que desempeña la autoridad institucional, pues sus cualidades de liderazgo y empoderamiento permiten motivar y direccionar al equipo de trabajo. No basta la buena predisposición del equipo, siempre es indispensable el acompañamiento y apoyo de quienes se encuentran liderando la institución.

Con relación a la dimensión cualidades del docente, registrado en el cuadro 1, resalta el código empoderamiento docente. De acuerdo a lo expresado por los participantes de la investigación, el empoderamiento se evidenció en el adecuado manejo de la base teórica de la estrategia. Los docentes demostraron convicción y direccionamiento de las diferentes actividades operativas y técnicas, y asumieron con buena predisposición retos y desafíos, dando lo mejor de sí. Otros códigos importantes constituyen la actitud cooperativa y solidaria, los mismos que se reflejaron en el apoyo que se brindaron entre ellos, al compartir experiencias que nutrieron el desarrollo de la estrategia. Tal como lo manifestó un docente "siempre estamos nosotros tratando de intercambiar todas las cosas buenas y malas que nos pasan, siempre estamos corrigiéndonos, estamos ayudándonos, estamos tratando de ayudarnos mutuamente" [D1]. Además, demostraron su actitud solidaria con los estudiantes, al asistir en forma puntual a sus requerimientos.

Otra de las cualidades evidenciadas en los docentes, constituye el liderazgo, el mismo que se ve reflejado a través de los códigos motivación y creatividad. Actitudes que se evidenciaron a través de su dinamismo y entusiasmo, propiciando la creación de un ambiente escolar favorable para el aprendizaje. Adicionalmente, algunos docentes demostraron iniciativa al plantear actividades novedosas. 
Las actitudes que manifestaron los docentes en la presente investigación coinciden con el rol del docente requerido para la implementación de los GI. Éste debe ser un líder al coordinar y organizar las actividades a cumplirse antes, durante y después de la implementación de la estrategia. En resumen, CREA (2018b) señala que el rol del docente en los GI implica la organización y definición de los grupos y preparación de actividades. Además, se constituye en un guía para los voluntarios, resuelve conflictos e inclusive apoya a las necesidades individuales (pág. 22). Por lo tanto, no cabe duda que parte del éxito en la implementación de los GI corresponde a la predisposición y rol que el docente cumple en la aplicación de la estrategia.

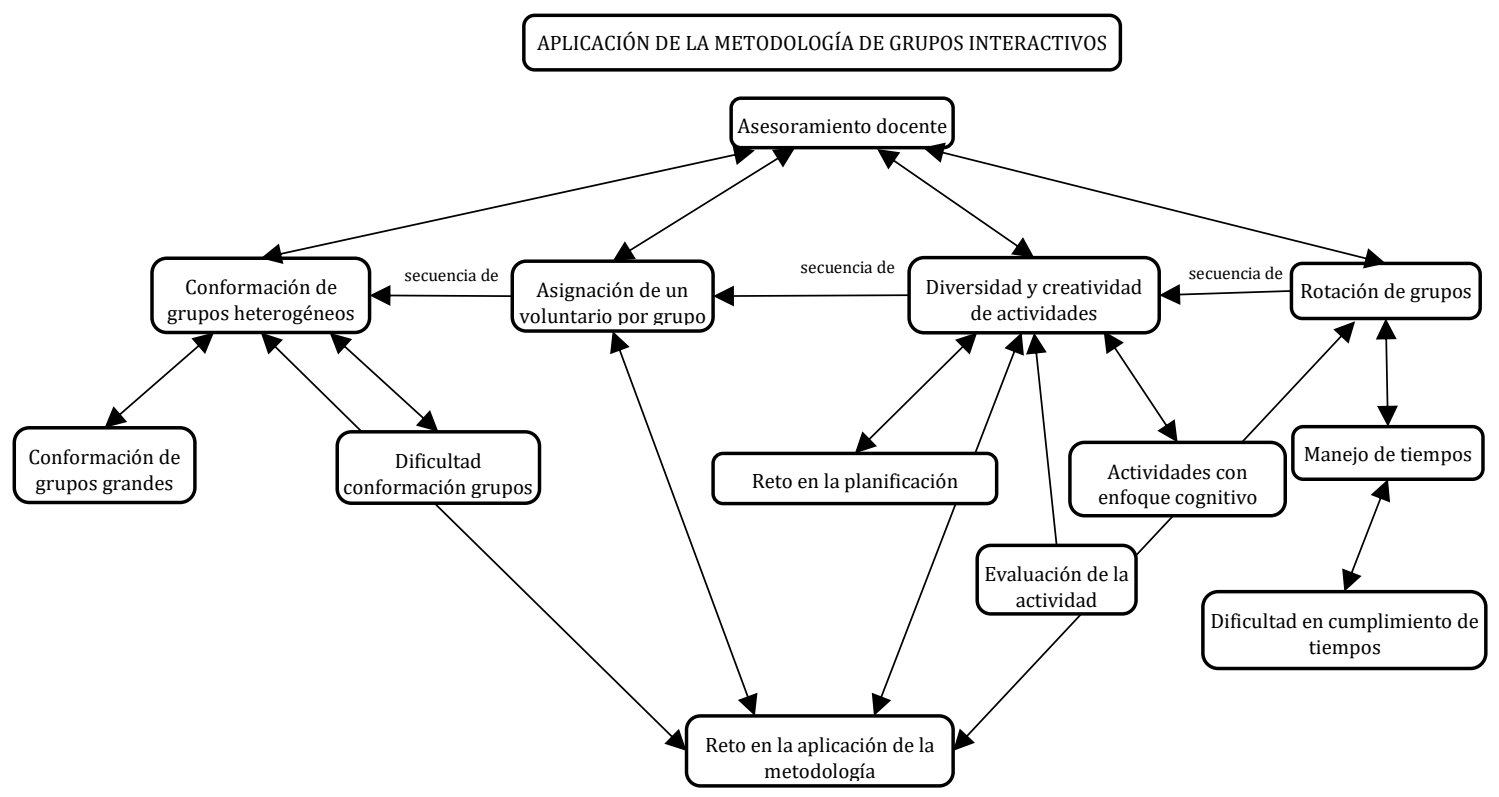

Figura 1. Aplicación de la metodología de Grupos Interactivos

Relacionado a la dimensión aplicación de la metodología de GI, tal como se observa en la figura 1, ésta se desarrolló en cuatro pasos. Estos se evidencian en los códigos: conformación de grupos heterogéneos, asignación de un voluntario por grupo, ejecución de diversidad y creatividad de actividades y rotación de grupos. Todas estas etapas son coordinadas y asesoradas por el docente. Resaltan aspectos antagónicos en la conformación de grupos heterogéneos y ejecución de actividades instrumentales. Además, reflejan dificultades en la planificación y aplicación de la metodología.

Sobre la base de lo expresado en la entrevista y grupos focales que se proyecta en el cuadro 1 bajo la dimensión aplicación de la metodología de los GI, la conformación de los grupos se caracterizó por la heterogeneidad e inclusión. El número de integrantes varió entre cinco a siete miembros. Las actividades propuestas en algunas asignaturas como Matemática, Física, Química y Emprendimiento fueron prioritariamente de carácter cognitivo. El equipo de voluntarios estuvo conformado por padres, madres de familia y representantes legales. En la ejecución de los GI, cada grupo de estudiantes estuvo bajo la responsabilidad de un voluntario. Dentro de este proceso se promovió la rotación tanto de voluntarios como de actividades. 
Se evidencia que se cumple con la condición de heterogeneidad y enfoque inclusivo de los grupos. Así lo expresan Oliver y Gatt (2010) "esta forma de agrupación inclusiva del alumnado consiste en la distribución de los alumnos y alumnas en pequeños grupos heterogéneos dentro de la misma aula..." (pág. 282). Sin embargo, no se ajustan a los parámetros entorno a la conformación de grupos pequeños, pues la recomendación es no sobrepasar los cinco integrantes. La estructuración de grupos pequeños garantiza la participación de todos, puesto que sus puntos de vista y actuaciones son tomadas en cuenta y se ven involucrados, hecho que no se advierte en grupos cuyo número es mayor.

Las actividades de carácter cognitivo propuestas por algunos docentes contradicen la directriz establecida en la metodología. Castro et al. (2014) señalan que se deben "establecer estrategias de enseñanza-aprendizaje orientadas a la dimensión instrumental del aprendizaje, con el propósito de capacitarles para responder a las demandas que se les van a plantear en la sociedad de la información" (pág. 178). La riqueza advertida de esta estrategia, radica en el fortalecimiento de aprendizajes instrumentales, anclados a una secuencia de procesos predeterminados que deben cumplirse en una sesión. En la experiencia de la institución, este aspecto se cumple de manera parcial. Las actividades planificadas por algunos docentes no propiciaron aprendizajes significativos.

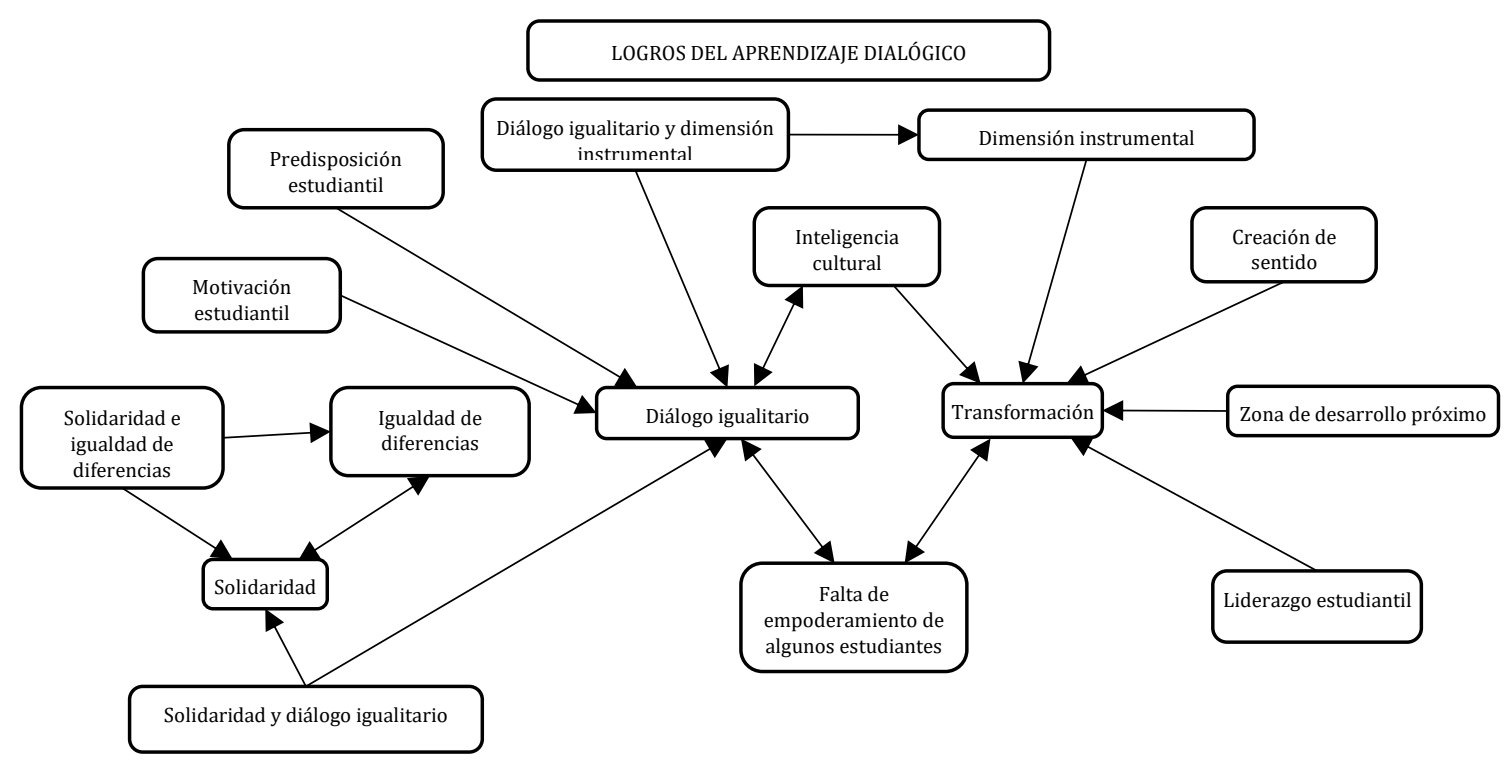

Figura 2. Logros del aprendizaje dialógico

La dimensión logros del aprendizaje dialógico, figura 2, se relaciona de manera directa con el tema de investigación. En tal virtud, se procede a detallar los resultados obtenidos a partir de la aplicación de la entrevista y los grupos focales.

Se cumplen los siete principios del aprendizaje dialógico. Así, al aplicar los GI se mejoró la convivencia dentro y fuera de la institución (transformación). Se promovió la democratización y participación de todos los miembros de la comunidad educativa en igualdad de condiciones (diálogo igualitario). La aplicación de los GI fomentó el respeto a la diversidad de formas de pensar, promoción de la interacción y potenciación de habilidades (igualdad de diferencias). Se reconocen las diferentes formas de pensar de los miembros del grupo y en función de ello se llega a nuevas ideas (inteligencia cultural). 
En los estudiantes, se despertó la concientización y el auto análisis respecto al aporte personal en el trabajo colaborativo (creación de sentido). Se incentivó la comunicación, interacción y participación de estudiantes tímidos e introvertidos e incluso de estudiantes con NEE (dimensión instrumental). Destaca el principio de solidaridad, pues se promovió el sentimiento de ayuda mutua, el trabajo colaborativo y el compañerismo. Los estudiantes con mayor grado de conocimiento y habilidades apoyaron a sus compañeros con dificultades de aprendizaje.

A más de los principios del aprendizaje dialógico, se potenció el liderazgo. La estrategia metodológica aplicada permitió que, en ausencia de líderes estudiantiles identificados, surgieran nuevos. Así también, se fortaleció la zona de desarrollo próximo (ZDP), la misma que gracias a la interacción entre pares se fortaleció y alcanzó niveles superiores de aprendizaje.

Si bien los logros alcanzados a través de la aplicación de los GI superan a las dificultades encontradas, se identificaron algunos retos. Entre los problemas identificados están la falta de empoderamiento de algunos estudiantes y escasa participación en el trabajo colaborativo. Ciertos estudiantes evidenciaron exceso de confianza en el trabajo de los líderes grupales y de compañeros con mayor desarrollo de habilidades y destrezas cognitivas. Al respecto Álvarez (2016) sostiene que:

Resolver ejercicios de manera dialógica es un aspecto especialmente costoso para el alumnado, acostumbrado a no negociar sus respuestas, a dar razones que justifiquen las opciones tomadas, etc. El reto es conseguir que haya un diálogo igualitario entre las personas del grupo (pág. 133).

Es quizá esta la razón por la que ciertos estudiantes no participan de manera activa. De ahí la necesidad de planificar estrategias que motiven a intervenir, a negociar sus respuestas, justificar sus opiniones. En sí, estimular al grupo para que intervengan todos los integrantes. Es de suma importancia que las actividades diseñadas por el docente tiendan a desarrollar y potenciar destrezas y habilidades requeridas. Flecha et al. (2003), a su vez reafirma que "el aprendizaje ya no depende tanto de lo que ocurre en el aula como de las interacciones que se establecen en todos los contextos en que las personas intervienen: colegio, domicilios, barrio, club deportivo, medios de comunicación, etc." (pág. 2). La educación debe ser el resultado de las interacciones del estudiante con todos los actores sociales y su contexto. El proyecto de $\mathrm{CdA}$ resignifica la estructura tradicional de la escuela, y se infiere que el concepto a trabajar de manera urgente es la cultura escolar. Es en este nuevo nicho de aprendizajes, donde la sistematización de procesos educativos permite fortalecer la cohesión social, a través de los aprendizajes dialógicos. 


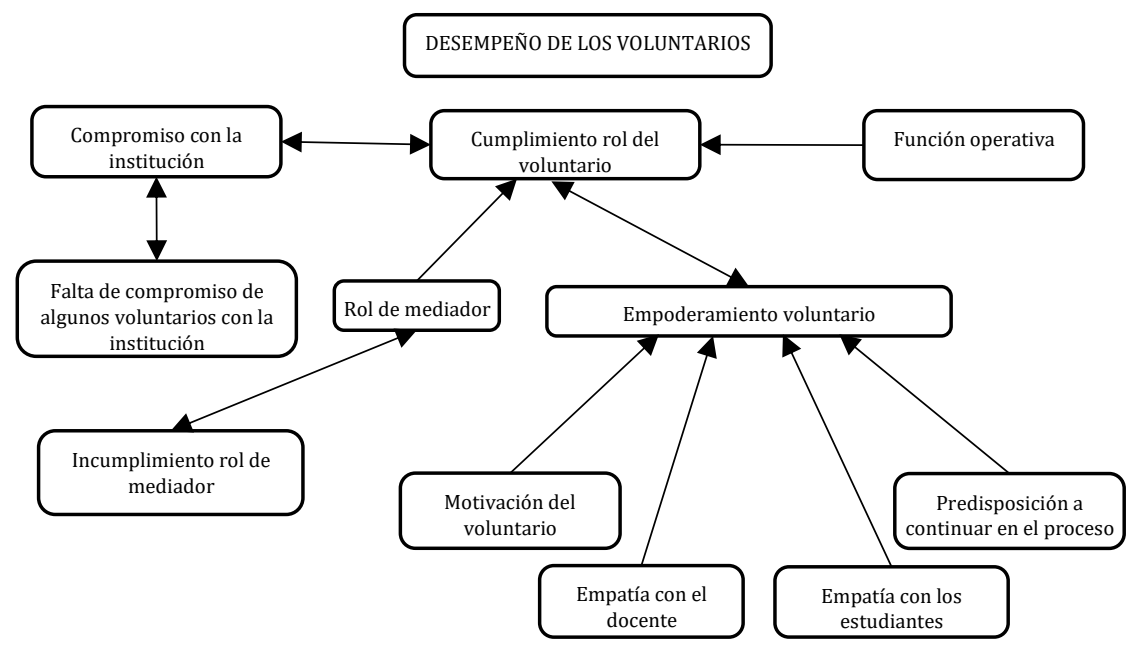

Figura 3. Desempeño de los voluntarios

La figura 3 relacionada con el desempeño de los voluntarios indica en términos generales el cumplimiento del rol del voluntario. Función que la cumple tanto en la parte operativa como de mediador. Se suman los códigos compromiso con la institución, empoderamiento del voluntario, y su empatía con el docente y estudiante. Sin embargo, existen aspectos que contradicen sus funciones como incumplimiento en su rol de mediador y falta de compromiso con la institución de algunos de ellos.

La creación de los códigos expresados en la figura 3 se sustenta en los grupos focales y entrevista que se muestra en el cuadro 1. El rol de mediador y su función operativa se evidencia a través de la participación activa en la organización y colaboración de las actividades propuestas por los docentes. Los voluntarios estimularon el trabajo equitativo de todos los miembros y promovieron la práctica de valores. Así también, se convirtieron en un apoyo y guía para el aprendizaje, al aclarar y direccionar las actividades a desarrollarse. En función de la experiencia positiva del voluntario en los GI, se revalorizó la función del docente en el aula y se expresó la predisposición a continuar en el proceso.

En síntesis, la participación del voluntario fue significativa, sin embargo, existieron aspectos que dificultaron el óptimo desarrollo de la estrategia de los GI. Por ejemplo, se evidenció la falta de compromiso por la inasistencia e impuntualidad de algunos voluntarios. Algunas madres de familia intervinieron en la resolución de las actividades. Este comportamiento, en lugar de constituirse en un apoyo para la estrategia, la entorpeció. No solo porque evitó que los estudiantes consoliden el aprendizaje por sí solos, sino también, porque el docente debía redireccionar su atención hacia ellos.

Lo citado en los párrafos precedentes resalta el aporte positivo del voluntariado bajo la dinamia de los GI. Este hecho concuerda con la investigación relacionada con el papel del voluntario desarrollado por Vieira y Puigdellívol (2013), quienes resaltan "de todas las informaciones recabadas podemos deducir con seguridad que los diferentes agentes (alumnado, profesorado y voluntariado, incluyendo las familias) perciben claramente el efecto positivo del voluntariado en el progreso académico del alumnado" (pág. 47). Si bien no es posible demostrar el peso específico que tiene el voluntariado en el avance académico, sí se puede afirmar que su contribución es significativa. 
Las experiencias relacionadas con la intervención de los voluntarios en la mayoría de los casos son positivas. Gómez et al. (2016), al trabajar con estudiantes universitarios en calidad de voluntarios señalan que "los aspectos positivos sobrepasan con creces a los aspectos negativos" (pág. 278). Se reafirma que los voluntarios son un elemento clave para facilitar el proceso de enseñanza aprendizaje. Es meritorio recordar que el éxito de la estrategia radica en la participación comprometida del voluntario, ya que sin éste la esencia de los GI se pierde.

\section{Conclusiones}

La aplicación de los GI como parte de las AEE permitió identificar varios logros expresados a través del cumplimiento de los siete principios del aprendizaje dialógico. Resaltan los principios de diálogo igualitario, transformación y solidaridad. El diálogo igualitario se evidenció por medio de la democratización y participación de todos los miembros de la comunidad educativa en igualdad de condiciones. El principio de transformación se expresó a través de la potenciación de los aprendizajes al mejorar la interacción en la comunidad educativa. La solidaridad se manifestó en el trabajo colaborativo donde los estudiantes con mayor desarrollo de habilidades y destrezas apoyaron a sus compañeros. Además de los principios dialógicos se resaltan como logros importantes el liderazgo estudiantil y la potenciación de la ZDP.

Los resultados positivos obtenidos en la presente investigación radican fundamentalmente en el cumplimiento de los roles tanto del docente como del voluntario. Los docentes de la UEA reflejaron empoderamiento en la implementación de la estrategia metodológica. La actitud cooperativa y solidaria, compromiso, liderazgo, predisposición y motivación, fueron aspectos que caracterizaron al empoderamiento. Los voluntarios por su parte, cumplieron con sus funciones tanto en la parte operativa como en su rol de mediador. Promovieron la participación igualitaria de todos los estudiantes, fortalecieron la práctica de valores como la honestidad. Se constituyeron en equipo de apoyo de los docentes al aclarar y direccionar las actividades propuestas. Adicionalmente, revalorizaron la labor del docente en el aula.

Los logros alcanzados en esta primera experiencia de los GI en la UEA se apoyaron en gran medida del equipo de soporte a través de procesos de capacitación, implementación y seguimiento constituido por agentes externos e internos, a decir Grupo Faro, Subsecretaría de Educación del Distrito Metropolitano de Quito y Distrito Educativo 17D08, Los Chillos, autoridad y docentes de la institución. Aspecto que en estudios similares se detectó como dificultad. De ahí la importancia de contar con un sistema de asesoramiento continuo que permita dar soporte y corregir errores en la implementación de la estrategia.

Durante la aplicación de la estrategia se identificaron algunas dificultades a nivel de docentes, estudiantes y voluntarios. En el caso de los estudiantes se evidenció en algunos de ellos la falta de empoderamiento, escasa participación, aporte y trabajo colaborativo. Las dificultades que exhibieron algunos docentes estuvieron relacionadas con la planificación de actividades instrumentales, manejo y aplicación de la estrategia e interiorización del enfoque metodológico. Respecto a los voluntarios, no existió la participación de todo el colectivo.

Los retos generados de esta primera experiencia giran alrededor de la consolidación de la estrategia. La interiorización del enfoque de los GI es determinante para alcanzar los principios del aprendizaje dialógico y potenciar el desarrollo de habilidades y destrezas. Para ello, es necesario proponer actividades colaborativas que despierten la creatividad y estén relacionadas con su entorno. Además, es necesario ampliar la comunidad educativa 
integrando a otros actores sociales en calidad de voluntarios, aspectos que permitirían fortalecer la inclusión y cohesión social.

Los GI, como estrategia innovadora de enseñanza, constituyen una experiencia positiva, pese a las dificultades propias que entrañan su implementación. Por tal motivo se precisa ejecutar a nivel institucional y nacional estudios de carácter transversal y longitudinal que permitan potenciar los resultados positivos obtenidos. Además, proyectar los principios del aprendizaje dialógico a otras instituciones educativas del país. 


\section{Agradecimientos}

Los autores dejamos constancia de gratitud y reconocimiento al invaluable aporte de la Unidad Educativa Antisana. Valoramos el aporte de docentes, estudiantes, madres, padres de familia y representantes legales, quienes a través de sus experiencias y criterios colaboraron en la consolidación del presente trabajo de investigación.

\section{Bibliografía}

Álvarez, C. (2017). Comunicación, entendimiento y aprendizaje en grupos interactivos. Investigación en la Escuela, 91, 90-105. DOI: https://doi.org/10.12795/IE.2017.191.06

Álvarez, C. (2016). Las dificultades para innovar en la escuela: el caso de los grupos interactivos. Investigación en la Escuela, (88), 127-138. https://bit.ly/2Qmovlm

Andrés Reina, A.B. (2016). Grupos interactivos como práctica innovadora y facilitadora de la inclusión educativa. (Trabajo de fin de grado, Facultad de Ciencias de la Educación, Universidad de Sevilla, Andalucía). https://bit.ly/2E4uQpv

Aubert, A., Flecha, A., García, C., Flecha, R., y Racionero, S. (2008). Aprendizaje dialógico en la sociedad de la información. Barcelona: Hipatia.

Castro, M., Gómez, A. y Macazaga, A. (2014). Aprendizaje dialógico y grupos interactivos en educación física. Retos: nuevas tendencias en educación física, deporte y recreación, (25), 174-179. https://dialnet.unirioja.es/servlet/articulo?codigo $=4555265$

Chocarro, E., y Mollà, S. (2017). Aportaciones de los grupos interactivos desde la perspectiva de estudiantes y voluntariado. Innovación educativa, (27), 6173. DOI: https://doi.org/10.15304/ie.27.4203

Community of Research on Excellence for All (2018a). Formación en comunidades de aprendizaje. Módulo 1. Introducción y bases científicas de las comunidades de aprendizaje. file:///C:/Users/MAVE/Downloads/download.pdf

Community of Research on Excellence for All. (2018b). Formación en comunidades de aprendizaje. Módulo 6. Grupos Interactivos. Recuperado de https://bit.ly/2K8p45v

Community of Research on Excellence for All (s.f.). Comunidades de aprendizaje. Aprendizaje dialógico. https://bit.ly/32RNh9K

Creamer, M. (2019). El aprendizaje dialógico: Transformación de la escuela en el marco de la implementación de comunidades de aprendizaje en Ecuador (Tesis Doctoral, Universidad Autónoma de Madrid). https://bit.ly/3aLZJL2

Flecha, R., Padrós, M., y Puigdellívol, I. (2003). Comunidades de Aprendizaje: transformar la organización escolar al servicio de la comunidad. Organización y gestión educativa, 5 , 4-8. Recuperado de https://bit.ly/3nyhUcd

García, R., Molina, S., Grande, L. y Buslón, N. (2016). Análisis de las interacciones entre alumnado y diversas personas adultas en actuaciones educativas de éxito: Hacia la 
inclusión de todos y todas. Latinoamericana de Educación Inclusiva, 10(1), 115-132. https://bit.ly/2EkPdOL

Gómez, M., Aguilera, A. y Prados, M. (2016), El voluntariado de la Universidad de Sevilla en los grupos interactivos de las comunidades de aprendizaje. Profesorado revista de currículum y formación del profesorado, 20(2), 278-295. https://bit.ly/379Lksp

Iglesias, B., de la Madrid, L., Ramos, A., Robles, C. y Serrano, A. (2013). Metodologías innovadoras e inclusivas en educación secundaria: los grupos interactivos y la asamblea de aula. Tendencias pedagógicas, (21), 63-78. https://bit.ly/2Q05JjH

Núñez, M., Espinoza, C., Acuña, C., Vargas, L. y Lagos, I. (2017). Grupos interactivos en aula y el incremento de los resultados de aprendizaje en lenguaje en un colegio vulnerable. Scielo Educ. rev. 33(e158882), 1-29. https://bit.ly/31xMkTN

Oliver, E., y Gatt, S. (2010). De los actos comunicativos de poder a los actos comunicativos dialógicos en las aulas organizadas en grupos interactivos. Revista signos, 43(2), 279294. https://scielo.conicyt.cl/pdf/signos/v43s2/a02.pdf

Ordóñez, R., y Rodríguez, M. R. (2016). Los Grupos Interactivos como metodología didáctica en Educación Secundaria: Estudio de casos en un centro constituido en Comunidad de Aprendizaje. Revista de Investigación en Educación, 14(2), 141-155. https://bit.ly/3aUMtE2

Ottone, E., y Hopenhayn, M. (2007). Desafíos educativos ante la sociedad del conocimiento. Revista Pensamiento Educativo, 40(1), 13-29. https://bit.ly/31TsnXE

Picardo, O., Escobar, J. y Pacheco, R. (2005). Diccionario Enciclopédico de Ciencias de la Educación (1ra ed.). https://bit.ly/34NEQOc

Rodríguez, J. (2012). Comunidades de aprendizaje y formación del profesorado. Tendencias pedagógicas, 19, 67-86. Recuperado de https://bit.ly/2KoEuGh

Valls, R. \& Kyriakides, L. (2013) The power of Interactive Groups: how diversity of adults volunteering in classroom groups can promote inclusion and success for children of vulnerable minority ethnic populations. Cambridge Journal of Education, 43(1), 1733. DOI: https://doi.org/10.1080/0305764X.2012.749213

Valls, R., Buslón, N., y López, I. (2016). Grupos interactivos: interacciones que aumentan el aprendizaje y la solidaridad. Padres y Maestros/Journal of Parents and Teachers, (367), 17-21. DOI: https://doi.org/10.14422/pym.i367.y2016.003

Vieira, L. y Puigdellívol, I. (2013). ¿Voluntarios dentro del aula? el rol del voluntariado en "Comunidades de aprendizaje". REXE. Revista de Estudios y Experiencias en Educación, 12(24), 37-55. https://www.redalyc.org/pdf/2431/243129663003.pdf

Zubiri, H., Vidu, A., Rios, O., \& Morla, T. (2020). Inclusivity, participation and collaboration: Learning in interactive groups. Educational Research, 62 (2) 162-180. DOI: https://doi.org/10.1080/00131881.2020.1755605

Licencia Creative Commons Atribución 4.0 Internacional (CC BY 4.0)

Revista Cátedra, 4(1), pp. 56-80, enero-abril 2021. e-ISSN:2631-2875

https://doi.org/10.29166/catedra.v4i1.2676 


\section{Autores}

BOLÍVAR VILLARREAL-YAZÁN obtuvo el título de Magíster en Gerencia Educativa en la Universidad Andina Simón Bolívar (Ecuador) en 2014. El título de Especialista Superior en Gerencia Educativa en 2004 en la citada universidad. El título de Licenciado en Ciencias de la Educación, Profesor de Enseñanza Media en la Especialización de Literatura y Castellano por la Facultad de Filosofía, Letras y Ciencias de la Educación de la Universidad Central del Ecuador en 1989.

Se desempeñó como rector de la Unidad Educativa Antisana, comunidad de Tolóntag parroquia de Píntag en el período 2016 a 2020. En octubre de 2020 asume el rectorado de la Unidad Educativa Amable Aráuz, institución educativa ubicada en la parroquia de Conocoto, Distrito Educativo 17D08 "Los Chillos". Ha participado en proyectos de investigación en calidad de investigador externo, aprobados por la Dirección de Investigación de la Universidad Central del Ecuador. Sus principales temas de investigación se enmarcan en el área de la limnología y en la didáctica de las Ciencias. Es autor de ensayos registrados en el Instituto Ecuatoriano de Propiedad Intelectual y de artículos publicados en revistas de Latindex.

VERÓNICA MAILA-ÁLVAREZ obtuvo el título de Magíster en Docencia Universitaria y Administración Educativa en la Universidad Tecnológica Indoamérica (Ecuador) en 2011. Título de Especialista en Diseño Curricular por Competencias en 2010 en la citada universidad. Título de Doctora en Biología por la Facultad de Filosofía, Letras y Ciencias de la Educación de la Universidad Central del Ecuador en 2001. Título de Licenciada en Ciencias de la Educación, Profesora de Enseñanza Media en la Especialización de Química y Biología por la Facultad de Filosofía, Letras y Ciencias de la Educación de la Universidad Central del Ecuador en 1998.

Actualmente es profesora titular de la Carrera de Pedagogía de las Ciencias Experimentales, Química y Biología de la Facultad de Filosofía, Letras y Ciencias de la Educación de la Universidad Central Ecuador. Ha participado en proyectos de investigación en calidad de directora e investigadora adjunta, aprobados por la Dirección de Investigación de la Universidad Central del Ecuador. Sus principales temas de investigación se enmarcan en el área de la limnología y en la didáctica de las Ciencias. Es autora de libros y artículos publicados en revistas de Latindex.

HELEN FIGUEROA-CEPEDA obtuvo el título de Magíster en Docencia Universitaria y Administración Educativa en la Universidad Tecnológica Indoamérica (Ecuador) en 2011. Título de Especialista en Diseño Curricular por Competencias en 2010 en la citada universidad. Título de Doctora en Biología por la Facultad de Filosofía, Letras y Ciencias de la Educación de la Universidad Central del Ecuador en 2005. Título de Licenciada en Ciencias de la Educación, Profesora de Enseñanza Media en la Especialización de Química y Biología por la Facultad de Filosofía, Letras y Ciencias de la Educación de la Universidad Central del Ecuador en 1997.

Actualmente es profesora titular de la Carrera de Pedagogía de las Ciencias Experimentales, Química y Biología de la Facultad de Filosofía, Letras y Ciencias de la Educación de la Universidad Central Ecuador. Ha participado en proyectos de investigación en calidad de investigadora adjunta, aprobados por la Dirección de Investigación de la Universidad Central del Ecuador. Sus principales temas de investigación se enmarcan en el área de la didáctica de las Ciencias. Es autora de libros y artículos publicados en revistas de Latindex y Open Academic Journal Index. 
ELIZABETH PÉREZ-ALARCóN obtuvo el título de Magíster en Docencia Universitaria y Administración Educativa en la Universidad Tecnológica Indoamérica (Ecuador) en 2011. Título de Especialista en Diseño Curricular por Competencias en 2010 en la citada universidad. Título de Doctora en Biología por la Facultad de Filosofía, Letras y Ciencias de la Educación de la Universidad Central del Ecuador en 2001. Título de Licenciada en Ciencias de la Educación, Profesora de Enseñanza Media en la Especialización de Química y Biología por la Facultad de Filosofía, Letras y Ciencias de la Educación de la Universidad Central del Ecuador en 1998.

Actualmente es profesora titular de la Carrera de Pedagogía de las Ciencias Experimentales, Química y Biología de la Facultad de Filosofía, Letras y Ciencias de la Educación de la Universidad Central Ecuador. Ha participado en proyectos de investigación en calidad de directora e investigadora adjunta, aprobados por la Dirección de Investigación de la Universidad Central del Ecuador. Sus principales temas de investigación se enmarcan en el área de la limnología y en la didáctica de las Ciencias. Es autora de libros y artículos publicados en revistas de Latindex. 